\title{
Research on Development Strategy of Tourism Industry in the Southern Sichuan Economic Zone
}

\author{
Hongying Li \\ School of Economics, Sichuan University of Science \& Engineering, Zigong, China \\ Email: lihongying314@163.com
}

How to cite this paper: Li, H.Y. (2018) Research on Development Strategy of Tourism Industry in the Southern Sichuan Economic Zone. Journal of Service Science and Management, 11, 83-93.

https://doi.org/10.4236/jssm.2018.111008

Received: January 1, 2018

Accepted: February 10, 2018

Published: February 13, 2018

Copyright $\odot 2018$ by author and Scientific Research Publishing Inc. This work is licensed under the Creative Commons Attribution International License (CC BY 4.0).

http://creativecommons.org/licenses/by/4.0/

\section{cc (i) Open Access}

\begin{abstract}
The Southern Sichuan Economic Zone is one of the earliest explored districts in Sichuan Province and has gradually become a new polar of economic growth. There are abundant tourism resources that ensure a strong momentum of economic development for the tourism industry; however, several problems still exist and await urgent solution. The proposed strategy of tourism industry development will contribute to moving the obstacles that hinders the development of tourism industry and achieving the transformation, upgrading and frog-leaping development of tourism industry in the Southern Sichuan Economic Zone.
\end{abstract}

\section{Keywords}

Development Strategy, Tourism Industry, Regional Cooperation, Southern Sichuan Economic Zone

\section{Introduction}

The Southern Sichuan area is one of the earliest explored districts in Sichuan Province, where has been found human remain about five to ten thousand years ago [1]. The concept of Southern Sichuan Economic Zone (SSEZ for short) was firstly proposed by Zhen in 1985, and originally it just includes cities of Zigong, Luzhou and Yibin. In the $11^{\text {th }}$ five years plan of Sichuan province, the SSEZ was redefined by adding Neijiang and part of Leshan to highlight its outstanding advantages and achieve new pattern of regional multipolarity of growth. In the past decade, the SSEZ has become an engine-like regional economic center with machinery, chemical industry, liquor industry, salt industry and tourism as its pillar industries. 


\section{The Significance of Tourism Development in the Southern Sichuan}

In a new era, the tourism industry in the Southern Sichuan is undergoing a frog-leaping development. On the one hand, as the whole nation is engaged in building a moderately prosperous society, the development model is gradually changing, so does the citizens' demand for tourism. Tourism industry has grown up to a new pillar industry. On the other hand, cities that lie between Chengdu and Chongqing are given large development space due to the approving of Chengdu-Chongqing Economic Zone, which accelerates the movement of the national industry chain from the east to the west. Therefore, the launch of development strategy of the tourism industry in the SSEZ complies with the development tendency of the current domestic economy in China.

There are matchless natural tourism resources in Sichuan, especially in the southern part [2]. Besides the human and cultural tourism resources in the Southern Sichuan also won a reputation both in China and abroad [3]. Tourism industry Development in the SSEZ facilitates to boost domestic demand, create new economic growth pole and minimize the disparities between Sichuan and other cities in the east part of China by developing cities group or economic district, building regional core city and promoting important industry.

\section{Status Analysis of the Tourism Industry in the SSEZ}

1) Strong momentum of development with unbalanced regional space structure

The SSEZ is the most important part in Chengdu-Chongqing Economic Zone and its tourism industry developed rapidly after 2000. The updated data on the provincial governmental webpage indicate that both the tourism income of the main cities in the SSEZ and kept a sound average growth of $26.2 \%$. Among the seven cities whose tourism income of the first half year of 2017 exceeded 20 billion RMB, cities of Leshan, Yi bin, Luzhou and Zigong are on the list. And Leshan took full advantage of its international tourism destination status and ranked the top with its first half-annual tourism general income of 37.5 billion RMB. The first half annual tourism incomes of Yibin, Luzhou and Zigong are 27.2, 22, and 20.5 billion RMB, respectively, while Neijiang fell far behind in this respect. Thus, we can say that the regional space of the tourism economy in the Southern Sichuan is fairly unbalanced.

2) Slight improvement of the competitiveness of the tourism products, but lacking of knock-out product

The tourism products in Southern Sichuan are composed mainly of sightseeing, recreation, cultural and ecotourism products. Reorganization and innovation have been conducted on the tourism products in the five cities in Southern Sichuan, for example Yibin plans to build an international ecological and cultural tourism destination along the upper Yangtze River, Luzhou is striving for constructing a triangle route for Chinese liquor industry, and Leshan endeavors 
to make itself a truly international ecotourism and cultural tourism destination, etc (Table 1). However, they still lack knock-out products with absolute advantages. The tourism products they promoted are mainly based on sightseeing and recreation. The tourists have alternatives since they are so similar to the tourism products provided by other areas.

3) Gradual improvement in tourism transportation, but with unbalanced ratio of transportation means

In recent years, the traffic construction in Southern Sichuan has been increasing vigorously. The travel time spent on the road among the five cities has been reduced due to the construction of railways, airlines and expressways, which extends their target markets. The circle of tourism expressways connected Yibin, Luzhou, Neijiang and Zigong and contributed to the formation of the one-hour economic center among the five cities in the Southern Sichuan (Figure 1). The accomplishment of Chengdu-Chongqing expressway (Chengdu-Leshan-Yibin-Luzhou-Hejiang-Jiangjin-Chongqing down town) reduced the time from Chongqing to Yibin to two hours. Besides, the construction of expressways from Chongqing to Kunming (Yu-kun expressway), Luzhou to Guiyang (Na-qian expressway), and Xiamen to Chengdu (Xia-rong expressway) reduced the travel time from the SSEZ to large cities in the southwest of China, such as Kunming and Guiyang.

Table 1. The status of reorganized tourism products of the five cities in Southern Sichuan.

\begin{tabular}{|c|c|c|}
\hline City & Reorganized tourism products & Recommended tour routes \\
\hline Leshan & $\begin{array}{l}\text { 1. Mount Emei-Leshan Giant Buddha scenic, } \\
\text { Qiliping International tourist resort } \\
\text { 2. Wutong-Jianwei district } \\
\text { 3. Muchuan ecological tourist district }\end{array}$ & $\begin{array}{l}\text { 1. Leshan Giant Buddha-Mount Emei } \\
\text { 2. Leshan Giant Buddha-Jiayang puddle jumper } \\
\text { 3. Leshan Giant Buddha-Heizhugou } \\
\text { 4. Emei Mountainside Qiliping } \\
\text { 5. Leshan Giant Buddha-Muchuan }\end{array}$ \\
\hline Luzhou & $\begin{array}{l}\text { 1. Luzhou old cellar scenic } \\
\text { 2. Huangjing Forest } \\
\text { 3. Taiping ancient town } \\
\text { 4. Fangshan Mountain } \\
\text { 5. Yaoba ancient town }\end{array}$ & $\begin{array}{l}\text { Routes of Luzhou famous wine, ecotourism and } \\
\text { tour of revolution }\end{array}$ \\
\hline Zigong & $\begin{array}{l}\text { 1. World of Chinese color lantern } \\
\text { 2. Wolong Lake International resort } \\
\text { 3. Qinglong Lake resort }\end{array}$ & $\begin{array}{l}\text { Tours of color lantern, simulated dinosaur, } \\
\text { salt culture and revolution }\end{array}$ \\
\hline Neijiang & $\begin{array}{l}\text { 1. Daqian cultural tourism industry park } \\
\text { 2. Longchang Guyu Lake Scenic } \\
\text { 3. Fanchangjiang cultural tourism industry park } \\
\text { 4. Luoquan ancient town, Wenjiang rural tourism }\end{array}$ & Tours of culture, natural scenic and foods \\
\hline Yibin & $\begin{array}{l}\text { 1. iangjiaba tourism resort } \\
\text { 2. Yangtze River international ecotourism landscape avenue } \\
\text { 3. The Southern Sichuan Leisure Valley } \\
\text { 4. Changning West Bamboo World international ecological } \\
\text { and cultural tourist resort }\end{array}$ & $\begin{array}{l}\text { Bamboo Sea Scenic Ecological health tour, Liquor culture } \\
\text { shrine tour, ancient folk culture tour, quietness-pursing } \\
\text { and body exercise tour, tour of revolution in Southern Sichuan }\end{array}$ \\
\hline
\end{tabular}

Data from Tourism Bureaus of the five cities in Southern Sichuan. 


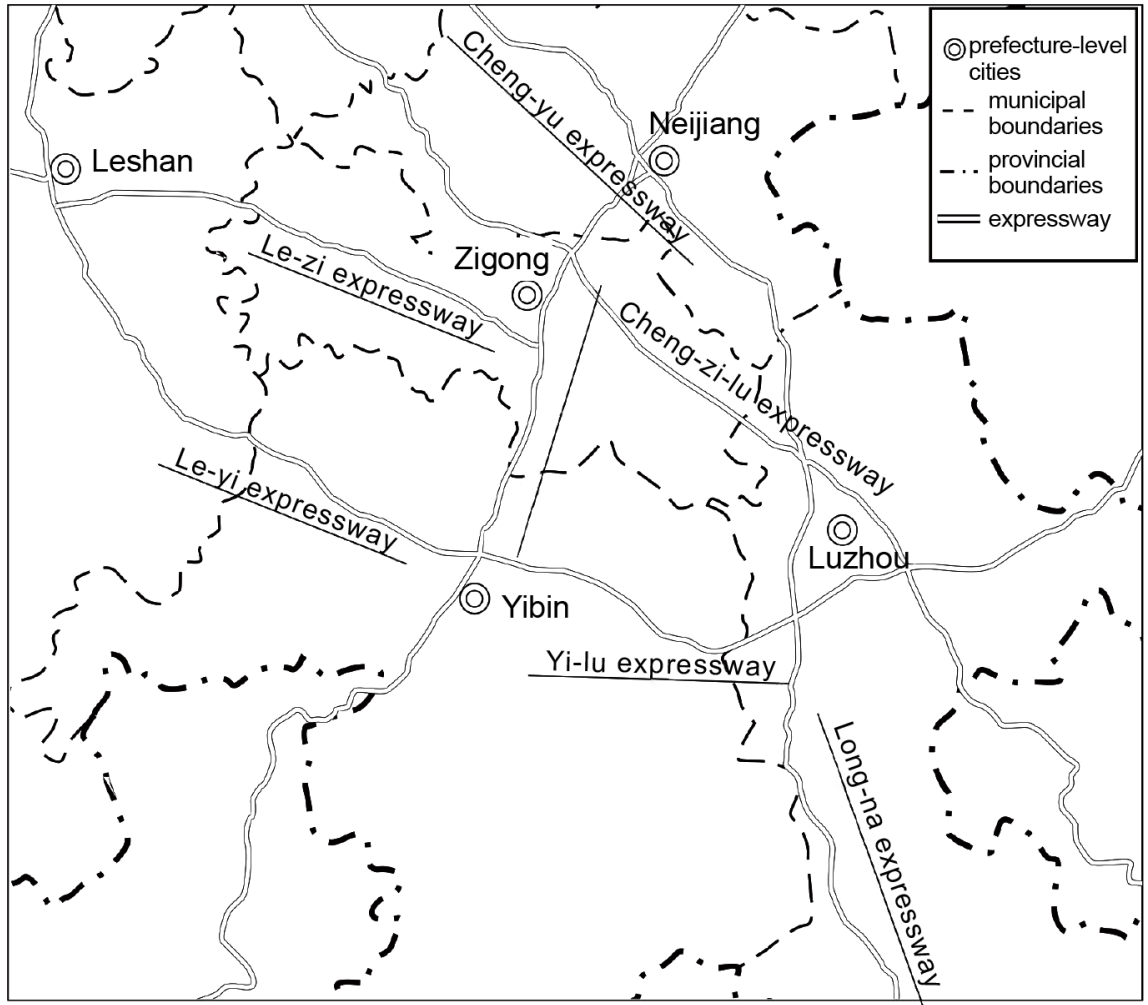

Figure 1. Expressway network in the SSEZ. (Modified from Li, P.J. [2])

However, it is obvious that the major transportation mean in Southern Sichuan is expressway, which occupies about $90 \%$ of the passengers flow volume in the five cities in Southern Sichuan, while the river, railway, and air transport occupies a small portion [4]. The Southern Sichuan is overly dependent on the costly expressway, with insufficient transport power, which probably grows into the bottleneck of the economic development in Southern Sichuan.

4) Strengthened regional cooperation, but lacking of a co-construction mechanism

The development strategy of regional linkage, integrating resources, complementary to each other, and developing together has facilitated the cooperation among the five cities in Southern Sichuan by the means of integrated tourism products introduction and marketing event, cultural and art festival and constructing circled tour routes in the Southern Sichuan, etc.

However, the five cities still focus on their own tourism resource exploration rather than cooperate with each other to obtain integrated advantages, which is the result of lacking a mutual motivation mechanism and will hinder the tourist agencies from competing with their adversaries selectively and cooperating with them to share a larger tourism market [5].

5) Development of smart tourism, but low-level regional tourist information service

China National Tourism Administration named the year of 2014 as Year of Smart Tourism, and meanwhile the provincial government also attached great 
importance to the development of smart tourism. Therefore, the construction of smart tourism is vigorous, with a hope of providing the tourists with more convenient and humanized service. Since then, some professional research institutes sprung up like mushrooms, presented by the Smart Tourism Research Center.

Not only haven't the customers been impressed by the Southern Sichuan tourism, but also the local citizens have no clear knowledge about the tourism products in the SSEZ. That's why they are not so interested in getting involved in the local tourism market. It reflects a fact that the tourism service in the SSEZ awaits great improvement. Undeveloped information level shows up as follows: 1) unsound regional tourism public information platform. Tourism information in the SSEZ is mainly issued by municipal or county official tourism website or enterprise website whose primary function is to release local governmental information or news rather than to provide travel tips for the tourists; 2) unavailable E-ticket or online booking and insufficient network marketing. A two-way communication channel between tourists and the scenic spots awaits establishment in forms of forum, community or special website.

\section{Development Strategy of the Tourism Industry in the SSEZ}

Though some accomplishment has been made in the tourism industry in the SSEZ, difficulties as mentioned before await settlement to achieve sustainable development of tourism industry in this region by establishing strategies referring to the tourism product, marketing, planning and layout, services, information and fundamental facilities, etc.

\subsection{In-Depth Exploration Strategy of Tourism Product}

Tourism mode has been changed from the traditional one to the modern further experience. Tourists have started to notice the historical and cultural significance to cultivate sentiments and expand their knowledge, which requires in-depth exploitation of the tourism products. All-level governments and tourism enterprises should focus on the heritage culture, salt and liquor cultures to implement the task of in-depth development of the tourism products. If possible, try to achieve the sugar cultural rejuvenation and explore color lantern and dinosaur culture.

\subsubsection{In-Depth Exploitation Strategy of Heritage Culture Products}

The tourists travel mode is dominated by sightseeing, even for visiting the global culture and nature heritages, such as Mount Emei and Leshan Giant Buddha. The cultural significance of these heritages awaits in-depth exploitation. For example, Gaint Baddha Park can be built along the Minjiang River by integrating Leshan Giant Buddha, Lingyun Tample, Wuyou Tample and Sleeping Buddha. By doing this, the park will integrate the mountain, river, Buddha and city and highlight the tourism theme of culture, sightseeing, ecology and recreation. Besides, the exploitation of Emei International Resort also should be deepened. Buddha, kung fu, food and hot spring are major elements of the Mount Emei 
culture and they will be explored in depth to accommodate the variety of the tourists.

\subsubsection{In-Depth Exploitation of Salt Culture Products}

The city of Zigong was built because of the thriving of salt industry and therefore the culture of this city is the accumulation and extension of salt culture. Salt culture conveyed by some trade association guild hall provides approaches for the tourist to review the local salt history and culture. The road for salt transport is not only an essential part of the salt culture but also necessary supplement to the culture of International Liquor Golden Triangle District. Besides, the bittern resource in Zigong is good for health. To build a salt health care resort and related brand is a significant direction for the in-depth exploitation of the salt resource in Zigong.

\subsubsection{In-Depth Exploitation of the Liquor Culture Products}

Liquor city of Wuliangye and fermentation cellars of Luzhou Laojiao, including scenic spots Liquor Saint Mountain, Museum of Liquor History and Floating Liquor Cups along Winding Water, should be given priority for in-depth exploitation as typical liquor culture products. Tourism related to liquor culture should highlight the production, brewing process and liquor culture. Festivals or exhibitions should be used to promote communications about the brewing skills and liquor culture among enterprises, and meanwhile to attract tourists to learn and experience the liquor culture. Besides, Bamboo Sea Scenic Area also can be get involved in the in-depth exploitation of liquor culture by introducing regular liquor tasting activities.

\subsubsection{In-Depth Exploitation of the Sugar Culture Products}

The City of Neijiang was vested unique tourism cultural and historical environment because of its sugar industry. To inherit the sugar culture and explore sugar industry heritage tourism, the first sugar industry museum in the mainland of China can be built (another one has been built in Taiwan). A tourism brand of "Sugar City" can be built by collecting historical and cultural data of the sugar industry to make urgent repair on the historical buildings and rebuild the sugar heritage and developing new sugar and sugar culture products.

\subsection{Tourism Destination Marketing Strategy}

\subsubsection{Characteristics of the "Heritage Corridor" in the SSEZ}

The Southern Sichuan is enriched natural and cultural heritages in dotted distribution which can be connect by a passageway for sightseeing. The passageway is called heritage corridor as the combination result of green development policy and cultural heritage protection. Two corridors should be built in the SSEZ, one for cultural heritage related to salt, liquor and sugar industries and the other for Leshan and Mount Emei. The two corridors connected by expressways will give birth to a tourism system of heritage corridor and the one-hour economic circle in the Southern Sichuan. 


\subsubsection{Image of the Tourism Destination in the Heritage Corridor}

Regarding to the image of the tourism destination, Leshan Giant Buddha and Salt-liquor Corridor should be chosen as two major brands. Innovations should be made in visual image, culture, consumption and environment protection to design and package the brands. All scenic spots and infrastructures should embody the core brand image. Introduction to the cultures of Leshan Giant Buddha, salt and liquor culture, Emei resort and corridor protection should be made domestically. However, detailed market demand analysis should be made before introducing tourism products with Chinese characteristics to tourist overseas.

\subsection{Tourism Coordinated Development Strategy}

Regional tourism coordinated development is the advanced mode to achieve regional cooperation. Local government, tourism enterprises and non-governmental organization cooperate to establish horizontal or vertical coordinated relationship, set up a "three-in-one" pattern and form multiple interaction joint force to promote tourism industry both in depth and width [6].

\subsubsection{Cooperate to Make General Plan of Tourism Development in Southern Sichuan}

Governments at all levels should take the lead to set up Southern Sichuan Tourism Development Commission, cooperate to make general plan of tourism development in Southern Sichuan, enhance the marketing and advertisement of tourism destination in Southern Sichuan, work together to build infrastructure, maintain competition order and clean up the regional ecological environment.

\subsubsection{Cooperate to Cultivate Large Tourism Enterprise}

Get small tourism firms into the tourism professional system by collaboration or alliance to build a large tourism group and form a spatial marketing network. Large tourism group can give play to its advantages in management, technology, financing and marketing, which contributes to strengthening the firms' cohesion and improving their competitiveness.

\subsubsection{Bridge Functions of the Non-Governmental Organization}

Tourism consulting or research associations can be built by combining universities, investment organization, salt or liquor enterprises and large travel agency to provide industry news and product information both in domestic and abroad for holding big tourism event. Besides, another approach to give play to the bridge function is to build tourism associations which will promote the standardization of the tourism industry.

\subsection{Tourism Guarantee Strategy}

\subsubsection{Deepen the Tourism Administration System Reform}

To realize reform and innovation in tourism administration system, government functions must be separated from enterprise management, and government regulation must be separated from management. Travel agency, scenic spot and 
restaurant should be operated as enterprise does. Traffic, business and infrastructure related to tourism also should avoid monopoly and encourage industry competition. Tourism administration department should transfer its function [6], delegate power to the market and endeavor to offer better public service, such as maintaining consumer's rights and interest, creating a fair and open consumption environment and maintain the market order.

\subsubsection{Strengthen Talent Troop Construction}

China National Tourism Administration announced that China is in shortage of tourism management talent, and the demand for skilled tourism majors will increase during the $13^{\text {th }}$ five year plan. Tourism-related education in the SSEZ is comparatively underdeveloped, lacking middle-high level talents and professional craftsmen. Therefore, it is urgent to establish talent system and strengthen the talent troop construction. Firstly, local government should provide policy and fund assistance to establish the talent cultivating system. Secondly, production, study and research in tourism department should be strengthened. Universities, colleges and enterprises should work together to do research on the planning of tourism products, market exploring and industry trends to provide solid scientific and technological guarantee. Forecasting the development trend and orientation of tourism industry can contribute to the construction of the cultivating mode of tourism talents [7].

\subsubsection{Accelerate the Barrier-Free Traffic Network Construction}

Convenient traffic indicates the thriving of tourism in a region, thus it is important to accelerate the construction of traffic network. The construction of traffic network in the SSEZ falls into the following parts: 1) accomplishment of expressway among major cities; 2) direct tourism channel to the scenic spots; 3 ) main road connecting major cities and counties; 4) and circle road connecting main scenic spots.

\subsection{Layout Strategy of the Tourism Industry Modification}

\subsubsection{Tourism Industry Clustering}

Tourism industry clustering is a phenomenon that a number of enterprises and organizations integrate to attract investment, technology, talent and information in order to achieve clustering benefit and scale economy. For example, build a tourism industry clustering district presented by liquor culture by integrating Wuliangye, Luzhou Laojiao and Langjiu.

\subsubsection{Diversification of Tourism Industry}

New tourism modes, such as industrial tourism, attractionless tourism and food tourism, should be introduced to accommodate the tourism industry development and tourists' diversified demands [3], meanwhile traditional tourism modes, such as sightseeing and leisure travel should be reserved. Industry tourism is in the beginning stage in China, with small market scale and consumer resource. However, there will be a big future in industry tourism with the economy de- 
velopment in the SSEZ due to its solid foundation of advanced salt, liquor and sugar industries. Attractionless tourism is a new travel mode with characteristics of autonomous, volunteer, self-service and free. These new modes broke the constraining of ticket, drove tourists to enjoy the journey rather than visit specific scenic spots [8]. People in Sichuan are picky at food, which contributes to the diversities of the Sichuan cuisine and its rich cooking culture that was embodied by Zigong dishes, Leshan Sweet duck, Dongpo cuisine (named after a famous poet in Song dynasty), Neijiang glazed fruit, Lizhuang garlic pork and Yibin burning noodles. Government at all levels should strengthen the advertisement of local food, lead tourist to taste the specialties and improve the food tourism, which will facilitate the further development of tourism industry in Southern Sichuan.

\subsection{Informatization Strategy}

\subsubsection{Construction of Tourism Information Platform}

Owing to the development of information technology, every corner in people's life is permeated by information service. For tourists, they fulfill their needs for value by information searching, and the perception value for service will affect their final choice. Tourists' perception of information value is closely associated with tourism demand [9]. Therefore, constructing an information platform for tourism industry is an important procedure to realize tourism integration in the SSEZ. The platform is composed of tourism information website and tourist hub. The five cities in Southern Sichuan should construct the website together, concentrating on providing service for tourists both in domestic and abroad. Information of scenic spots, traffic, hotels and travel destinations also should be posted on the website to build a big information market where tourism -related information can be shared. However, website is not the only way to provide professional tourism information, and sometimes, face-to face consulting and leaflet distribution are much more effective, therefore tourist hub rises in response to the proper time and conditions. Tourist hub is expected to provide free tourism service for the public and set up enquiry points at traffic centers and major scenic spots to offer detailed regional tourism map, introduction to scenic spots, food, culture and travel routes for tourists.

\subsubsection{Smart Tourism Construction}

Smart tourism is not only the trend of tourism industry development but also an essential part of the tourism informatization strategy of the SSEZ. Leshan and Yibin have been listed as smart tourism pilot cities and the Sichuan Smart Tourism Key Research Center was established at Sichuan University of Science and Engineering, which qualifies the Southern Sichuan to establish smart tourism system. These pilot cities, scenic spots and research institutes should play leading role in providing humanized and convenient service for tourists by application of technologies, such as cloud calculation, internet of things and so on. Smart tourism construction comprises tourism service, tourism management and 
tourism products marketing. Take building self-driving trip application for example. This software is expected to locate driving route automatically and provide information about the traffic status and park lot. Construct database of the scenic spots GIS, passenger flow, monitoring and environment to achieve scientific management in scenic spots. Cloud calculation can be used to monitor public reaction and make data analysis to explore future tourism attraction and interest and guide tourism enterprise to develop new products and determine scientific marketing theme.

\section{Conclusion}

Tourism industry in the Southern Sichuan is facing opportunity for frog-leaping development under new period and circumstance. Although accomplishment has been made in tourism industry in the past years, tourism income and the number of accepted tourists keeps an increasing trend and the tourism products are gradually diversified, it is essential to formulate tourism development strategy when facing furious competition in a new period. It will facilitate the tourism industry transformation and upgrading and achieve frog-leaping development if strategies of products, marketing, coordination, guarantee, layout and informatization can be firmly implemented.

\section{Acknowledgements}

The authors would like to acknowledge the supports from Sichuan University of Sciences \& Engineering (No.2017RCSK01), Industry Transformation and Innovation Center of Zigong Social Sciences Association (No. 2017CYZX005), Resource-based City Development Research Center (No. ZYZX-YB-1502), Research Center for International Transmission of Sichuan Liquor Culture (CJCB2017-03) and the Key Research Base of Humanities and Social Sciences of Sichuan Education Department (No. XXTYCY2015C01).

\section{References}

[1] Zhen, L. (1985) An Analysis on the Development Prospects of the Southern Sichuan Economic Zone. Journal of the Southwest Teachers College, 8, 54-60.

[2] Li, P.J., Chen, Y.J., Li, H.Y. and Chen A.D. (2015) Types and Development Value of Tourism Geology Resources in Southern Sichuan. Resource Development and Market, 31, 881-885.

[3] Li, P.J., Chen, Y.J. and Li, H.Y. (2016) Some Thoughts on the Development of Geological Tourism Resources and Tourism Industry in Southern Sichuan. Journal of Southwest Petroleum University (Social Sciences Edition), 18, 52-56.

[4] Zhang, L. (2008) Research on Constricting Transportation Network in South Sichuan Province Tourism Circle. Southwest Jiaotong University, Chengdu.

[5] Wang, D. (2010) A Research on Industrial Tourism in Southern Sichuan. Sichuan Normal University, Chengdu.

[6] Zhang, H.H. (2008) The Development of Regional Tourism Based on Synergy Theory-Take Northwest Region as an Example. Northwest Normal University, 
Lanzhou.

[7] Xu, D.B. (2016) Study on the Cultivating Mode of Undergraduate Talents in Tourism Management: Literature Review, Analysis and Discussion. Journal of Service science and Management, 8, 496-501. https://doi.org/10.4236/jssm.2015.84050

[8] Guo, W. (2010) No-Scenic Spot Tourism the Emergence of a New Form of Tourism and Its Impact to Tourism Industry. Tourism Forum, 5, 566-571.

[9] Deng, Z.M. (2016) Tourism Information Value and Its Hierarchical Structure. Open Journal of Social Science, 4, 10-16. https://doi.org/10.4236/jss.2016.48002 